\title{
OSI Publishers Stakeholders Report
}

\author{
Wim Van der Stelt
}

At the OSI 2017 meeting in Washington, D.C., thirteen attendees were publishers. At minimum, this demonstrates that publishers heavily engage with the services they provide to research communities and consider the discussions about open science to be important.

It is crucial nevertheless to understand that different publishers have diverse opinions, policies and strategies and-because many of them compete with each other-it is in many cases forbidden (by law) and/or unwanted (for competitive reasons) to share these opinions, policies and strategies. It is not possible, therefore, to have one combined opinion for this stakeholder group.

There is another reason why publishers at the OSI2017 meeting are not necessarily united: Attending publishers are diverse with respect to size (e.g. Elsevier vs. Annual Reviews), background (e.g. commercial entities like Springer Nature and notfor-profit societies like IEEE), and dominating current business models (e.g. large publishers with mixed business models vs. PLOS and Hindawi operating with an open access model only).

The one thing that unites all publishers is a dedication to providing optimal services to their customers: researchers, students, institutions, libraries, research funders, governments, and commercial entities all around the world. Together, publishers contribute to creating a global research publication ecosystem in which they validate content, facilitate the workflow of reporting the results of research, organize peer review, perform many quality measures (including e.g. plagiarism checks), safeguard integrity, add metadata and other structural elements to the content to make this content available, discoverable, usable and visible at scale, while assuring the availability of that content for perpetuity.

These main functions of the publishing industry guarantee a clear and sustainable infrastructure for the scholarly record, that in principle is agnostic about business models different publishers might use.

Publishers are important drivers of innovation in scholarly communication; they actively support (in many cases in time, money and brainpower) many innovative organizations like Crossref, Force11, ORCID and RDA. They also support organizations that care about standards, like COPE and COUNTER. Additionally, publishers are the main contributors to archiving solutions such as CLOCKSS and Portico.

Many publishers are a members of the Open Access Scholarly Publishers Association (OASPA).

Despite their diversity, publishers do in general care about innovation, and open science is an important subject. For that reason, publishers are happy to be actively 
involved in initiatives such as OSI. OSI provides an inclusive forum to engage with many stakeholders in the discussion and has global intentions.

Publishers also have concerns. There is little engagement from funders at the OSI meetings and there is virtually no attend- ance from the Global South. It also is unclear what the exact impact of the initiative can be, particularly as it will be very difficult to unite all stakeholders in recommendations or even opinion statements. Finally, publishers are concerned about the long-term viability and vulnerability of the organization, as it is basically a one-manshow in its current form.

\section{Publishers Stakeholder Group:}

Carrie Calder, Director, Business Operations \& Policy, Springer Nature

Holly Falk-Krzesinski, Vice President for Strategic Alliances in Global Academic Relations, Elsevier

Brad Fenwick, Senior Vice President, Elsevier

Ann Gabriel, Vice President Global Academic \& Research Relations, Elsevier

William Gunn, Director of Scholarly Communications, Elsevier

Aimee Nixon, Head of Open Access Publishing, Emerald

Paul Peters, CEO, Hindawi

Tom Reller, Vice President Global Corporate Relations, Elsevier

Dave Ross, Executive Director, Open Access, SAGE Publishing

Concetta Seminara, Editorial Director, Social Science \& Humanities Journals, Routledge/Taylor \& Francis

Caroline Sutton, Head of Open Scholarship Development, Taylor \& Francis

Andrew Tein, Vice President, International Government Partnerships, Wiley

Wim Van der Stelt, EVP Strategic Relations, SpringerNature 